\title{
The Combining of Intrinsic and Extrinsic Motives for Employing OTT Media and Comprehending the Audience's Gratification in Malaysia
}

\author{
ASMA MD ISA \\ WAN AMIZAH WAN MAHMUD \\ WAN IDROS WAN SULAIMAN \\ Universiti Kebangsaan Malaysia
}

\begin{abstract}
This article provides a conceptual framework for inspiring the audience towards the growing demands for Over-The-Top (OTT) media, as well as the evaluation of user satisfaction in Malaysia's services. The advance of technology and innovation has made possible the integration of telecommunications and broadcast networks, and, in doing so, has blurred the borders of the telecommunications and broadcasting industry. In this analysis, the motivation of the viewer as an entire indivisible mechanism to achieve media pleasure, both intrinsic and extrinsic elements, and, ultimately, formulate a conceptual framework, are described. Nonetheless, researchers have struggled in balancing intrinsic and extrinsic motivations, especially in recognising the interdependency between the origins of media consumer desires and incorporating them in conjunction with media and connectivity theories, which were typically too expansive to be implemented in convergence digital media. Therefore, this paper discusses the possibilities for combining intrinsic motivations with extrinsic ones. The interconnected conceptual framework provides a comprehensive view of the analyses and intentions of the engaged audiences in Malaysia for OTT media. This study also suggests further research that would include different measures and a larger sample as well as other areas, which could result in better understanding of the relationship between the variables.
\end{abstract}

Keywords: OTT media, convergence, motives, gratification, conceptual framework.

\section{INTRODUCTION}

Currently, 70 per cent of the modern world is Internet-based, and academics and professionals have begun to show an understanding of how an active public utilises new media to meet social, cognitive, and psychological requirements. This article discusses and seeks to understand why when people are searching the media, they usually like to serve their goals in an entirely fresh sphere. Manovich's suggestion (Manovich, 2001) was that computing and media embodies the union of two separate courses of history: media technology and computing. The active viewers are known as broadband users, who demand sole sources of education, amusement, and knowledge, and, currently, no longer rely on linear television. One is now able to adopt several devices that permit one to exhaust content privately. The Internet-enabled spread has drastically transformed viewers' usage, type, and video content. Besides that, there is a dispute concerning the motivation for the institution of television services that involve consideration of the vision that proposes the consumer as the final factor of growing or more usage of Internet-based application services. This applies to user-generated content, online streaming, home digital video networks, and video-ondemand.

This paper mentions the content that is distributed on the Internet but is not restricted to the Content Delivery Network (CDN) as over-the-top media (OTT media), or popularly accepted by the public as Web TV or Internet TV. It greatly expands the service to a large- 
scale market mechanism or channel that utilises the Internet, where the platform of operation in Malaysia is still not regulated.

\section{LITERATURE REVIEW OR RESEARCH BACKGROUND}

Currently, the switch to the digital platform represents one of the most pertinent universal breakthroughs in the broadcasting domain. The novel colour TV experience has been loved by many families since 1928 (Sterling \& Kittross, 2002). In the 1950s, for instance, videotape recording (VTR) was manufactured, and, in the 1980s, video cassette recorders (VCR) were developed. The Industrial Revolution led to technology advancement in which equipment was formed based on its usability in the TV sector. After that, in the 1990s, digital satellite dishes were created (Sterling \& Kittross, 2002) domestically under the Pay TV satellite segment. This was one of the highly demanded electronic pieces of equipment. In 2000, digital video discs (DVDs), specifically in the home entertainment industry, grew into a critical player in the market. This occurred because each film studio created movies in the form of a digital versatile disc (DVDs). Then, consumers determined to switch to the DVD for entertainment from the video home system (VHS). There are two essential elements to highlight here. First, technology promotion is formed through an operating system (OS) and PC architecture, which enables users to employ DVDs as a media centre like playing MP3s, VCDs, and CDs, to a fullfledged PC capability. Second, it is imperative that the service characteristic of digital advancement and the convergence of various modes of media eases the complex characteristics of its end-users. At present, although the DVD and VCD player are no longer provided in each personal computer, the user can subscribe, download, or stream the content online conveniently.

Although the Internet was once exclusively utilised by the Defence Department as a communications medium and between research teams, presently, it maintains numerous Internet-based applications, such as video sharing and online games (Dux \& Kim, 2018), UGC, and over-the-top media (Ganuza \& Viecens, 2014). Both fixed broadband and mobile Internet access are publicly available in Malaysia, digitisation and convergence are evident, hence, promoting the value for consumers from OTT providers through Internet services. In Malaysia, it is established that consumers do not have to consider making any commitment in respect of the service provided by the licensee providers in Malaysia. OTT contributors can easily grant the content to its clients. Consumers benefit from the abundance of alternative methods to the services they prefer based on interests that match their spending plan. OTT providers have also broadened their online shopping portfolio, and include e-hailing, devices, cloud hosting services, smartphone operating systems, online shopping, maps to navigation routes, and others. The broad categories of Internet-based applications that currently operate in Malaysia as the leading platform are summarised in Figure 1. 


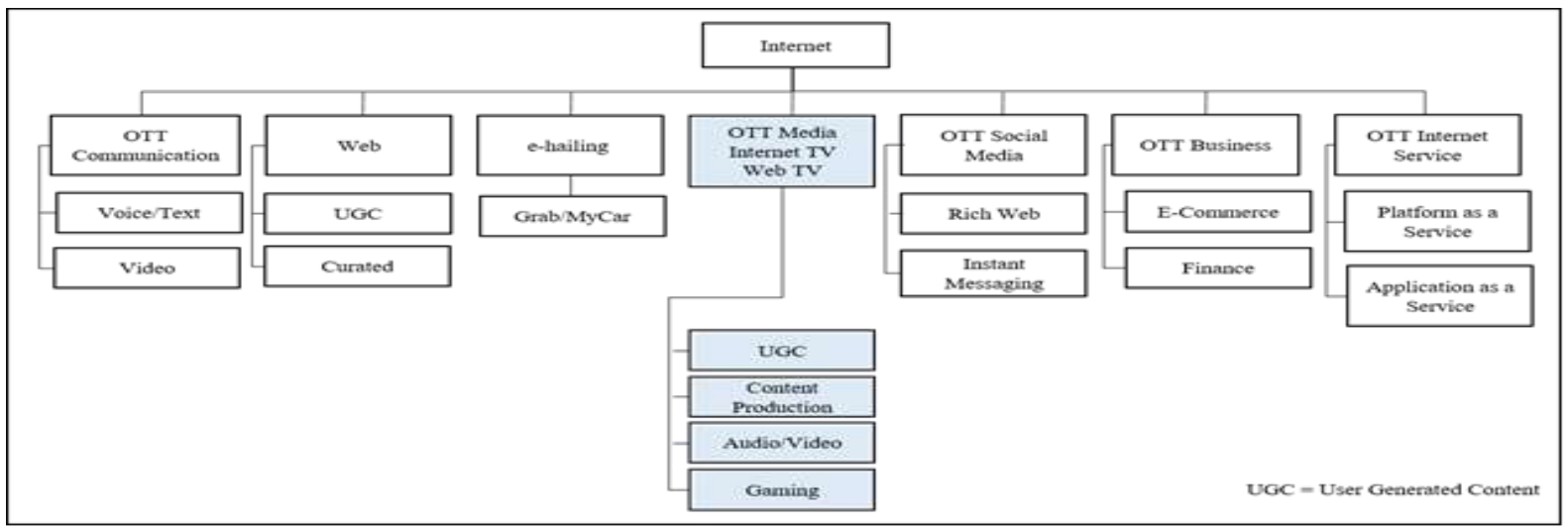

Figure 1: Internet service classification

Since the Internet was first launched for public utilisation to the public in Malaysia in 1995, it has become necessary for a distinct media platform that supersedes the old media with a new dimension. In recent years, there has been much debate concerning the users' motive to seek content to achieve gratification. The speedy adoption of latest technology and growth in broadband service have resulted in customer's sway to various application services that changed the lifestyle into digital with mobility. Internet connection is always couple with OTT media that appear when deliberating online content services. It is clear that the Internet has become a catalyst for digital media broadcasting via online content delivery. Each content contributed by OTT media players can also be reached via tablets, smartphones, smart TV, personal computers, and any other suitable devices with an Internet link.

The emergence of OTT media in Malaysia began when Media Prima Berhad launched Tonton in 2010, OTT media was in its infancy. OTT media, generally known as Internet TV and became prominent in 2012 (Latiff, Ridzuan, Mohideen, Anuar, \& Shukri, 2016). Global crossborder nature of OTT services leads to a situation where the OTT global players had to expand its footprint to another country. In 2016, Netflix landed in Asia Pacific continent including Malaysia following the announcement by Co-founder and Chief Executive of Netflix, Rees Hastings (Hegedus, 2016). Digital TV Research (Digital TV Research, 2016) in its report issued on October 2016, reported that OTT players had grown its coverage as tabulated in Table 1.

Table 1: OTT media footprint in Asia

\begin{tabular}{lcl}
\hline \multicolumn{1}{c}{ Country } & No of Player & \\
\hline Australia & 5 & Netflix, Stan, Presto, Foxtel Play, Amazon Prime \\
China & 4 & Youku Tudoi, TMall Box Office, Iqiyi, QQ Tencent Video \\
Indonesia & 6 & Netflix, Iflix, HOOQ, Tribe, Catchplay, Viu \\
Hong Kong & 4 & Netflix, GOTV, MyTV Super, Viu \\
Japan & 8 & Netflix, Amazon, Hulu, Tsutaya, U-Next, Avex dtv, au Smart Pass, UULA \\
Malaysia & 7 & Netflix, Iflix, Astro OD Plus, Tonton Premiere, Viu, HOOQ, Catchplay, \\
Thailand & 3 & Netflix, Iflix, HOOQ \\
Singapore & 5 & Netflix, Iflix, HOOQ, Viu, Catchplay \\
Vietnam & 3 & Netflix, Iflix, HOOQ \\
Philippines & 3 & Netflix, Iflix, HOOQ
\end{tabular}

Source: Digital TV Research, 2016

Today, billions of people around the world including Malaysian are currently in lockdown have led to increased content consumption not limited to increasingly sharing, commenting on, streaming, and researching online content. This study tries to provides a 
foretaste into the largest dataset of Malaysian web TV audience motives as well as perception for thriving during and beyond the pandemic for OTT's media. Throughout of MCO, the demand of content aired via OTT media such as Netflix and Tonton heavily spurred while being stuck at home to curb the Covid-19 spread (Ida Lim, 2020).

Despite of booming demand of content aired via OTT media platform, there is a rise of debated issues in particular over uncensored content such as LGBTQ (Parliament of Malaysia, 2019), sexually oriented, over used ' $F$ ' word is concerned (Asma, Wan Amizah, Wan Idros \& Muhammad Adnan, 2019) and violence which could bring bad influence to Malaysian society. Most of OTT Media players such as Netflix have no censored content of the shows, movies and drama series that are available. Hence, the audiences have a full access to the uncensored version of movies and TV series, which can be accessed within the OTT Media player's data storage (Lavanya \& Ramanchandran, 2011; Asma et al., 2019).

At this moment, there are no policies, i.e. censorship, reporting, comply with service quality parameters and/or rate regulation imposed on OTT players (Becot, Bertin, Crom, Frey, \& Tuffin, 2015). Lack of efficient regulation and self-regulation of OTTs demands settlement of a discussion platform where all these issues could be put forward and solved. Therefore, this paper attempts to build contemporary studies to investigate both intrinsic motive and public perception towards uncensored content broadcasted via OTT media platform and its relationship with audience's gratifications in Malaysia.

\section{THE RATIONALE FOR THEORY SELECTION}

This article concludes that the majority of previous researchers employed the theory of Uses and Gratification (U\&G) as a theoretical model for their research. The U\&G theory is a convenient method for addressing the domain of mass communication. Katz and Foulkes (1962), who commented further on the U\&G theory, reported that it delivers greater attention to the customer or the audience than to the right information by saying, "What are people doing with the media? Instead of "What are the media doing to the people?" Despite Lazarsfeld's initiation in 1947, the theory is still applied in modern studies in the area of research involving smart devices (Greer \& Ferguson, 2015) serving as multi-screen viewers on televisions (Dias, 2016), binge-watching (Schweidel \& Moe, 2016) YouTube as a respectable information source (Faroqi \& Suryanto, 2017) and online games (Dux \& Kim, 2018). Furthermore, research has implemented the U\&G theory, which focuses primarily on young people in terms of media influence on audiences (Wagner, 2016; Schweidel \& Moe, 2016). This theory relates to the purpose and pleasure of social media. This article aims to extend further the theory of U\&G on OTT media purposes as an intrinsic motivation for the audience in Malaysia.

The Expectation Confirmation Theory (ECT) is a cognitive perspective that provides the service providers' perceived performance and demanded services that influence client satisfaction. In a two article series by Richard L. Oliver (Oliver, 1980) the theory structure was established. This theory of ECT (Oliver, 2015) has been frequently applied in the marketing domain (Fudurić, Malthouse, \& Viswanathan, 2018) concerning the motives for switching, partly or completely, from cable TV contributors to over-the-top (OTT) media (Fudurić et al., 2018), binge-watching (Merikivi, Mantymaki, Salovaara, \& Zhang, 2016) and smart devices (Greer \& Ferguson, 2015). Making a comparison of what the consumers want and the services rendered by the OTT Media providers could lead the core motivations to subscribe to the OTT Media services for potential customers. In this article, it is realised that the ECT theory is 
usually subjected to post-buying conduct. However, this article attempts to apply this theory as an extrinsic motive for the viewers, which reviews the fact that most OTT media providers promote attributes, such as free trials, budget-friendly subscription fees and convenience components, and no business adverts for most of their viewing that may adversely alter their decision to sign up with OTT media services.

Over the last several years, there has been a considerable amount of discussion regarding the users' motive to explore content to achieve pleasure. Nonetheless, there has been comparatively little analyses to identify the external factors, particularly the influence of OTT players' commitment to users, advertising, and purchasing components that entice the client to support OTT media. The combination of internal and external factors influences users to shift from linear TV to the OTT platform and to use media to satisfy their cognitive, social, and psychological requirements, fundamentally, the intrinsic and extrinsic grounds.

This article is a collective initiative in designing, unfolding, and developing the existing U\&G and ECT theories. Generally, this article is theoretically driven so that the research clarifies the audience's reason sensibly and rationally regarding the behaviour and phenomena of the subject being studied. Accordingly, this article proposes that the assimilation of both the U\&G and ECT theories provides sound grounds to examine the factors that cause users to watch online streaming content, such as Netflix, Tonton, iFlix, Dimsum, Astro-on-the-go, and HyppTV Everywhere. It suggests that this theory is the most suitable for this research analysis for defining the intrinsic and extrinsic motives to obtain gratification.

\section{PROPOSED CONCEPTUAL FRAMEWORK}

The ultimate goal of this article is to consolidate the theories of U\&G and ECT as individualistic variables (IV) following Mulder's (Mulder, 2006) viewpoint that not every concept can define reality. U\&G is the favoured approach for understanding viewers in the setting of mass communication, while ECT is preferred for comprehending consumers in terms of postpurchase behaviour in the marketing field. Both theories examine the results of service consumption towards satisfaction, which is the dependent variable (DV) in this study. The driving factor of OTT media in this study is based on Richard Oliver's (Oliver, 1980) synthesis of the U\&G theory (Katz \& Foulkes, 1962) and ECT philosophy (Oliver, 2015). This article uses $U \& G$ theory to describe the audience's intrinsic motives to view OTT media while ECT describes the motives controlled by the extrinsic factors, in particular, offers by OTT players that shape clients' resolution to subscribe to OTT media. This article determines whether both intrinsic and extrinsic motives could be accomplished, and whether the audience will obtain pleasure in media consumption.

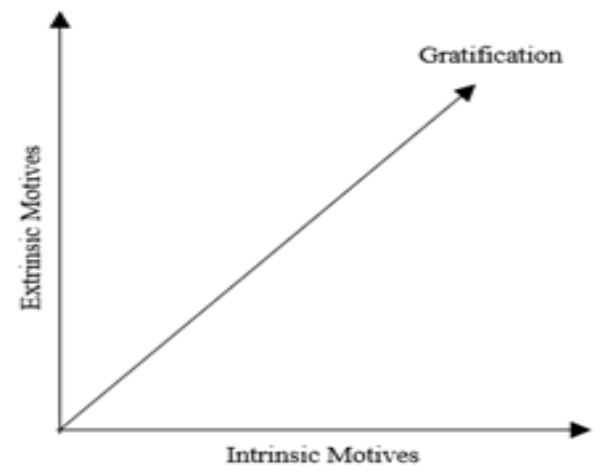

Figure 2: The relationship between intrinsic and extrinsic motives and gratification 
The more intrinsic and extrinsic motives that are obtained, the higher the level of the audience's accomplishment of gratification. An audience that profits from watching OTT media is one that applies the OTT media effectively based on the intrinsic and extrinsic motives to gain pleasure. This paper expects that any audience that chooses the OTT media to experience gratifications will be an engaged audience in the heterogeneous convergence period. Extrinsic motives arise from outside of the individual while intrinsic motives come from within.

\section{Intrinsic Motives:}

In this study, the exceptional technological parts and accomplishments of media management are indispensable to understand the evolution of the OTT media platform. The paper adopts a user-centric methodology and uses the U\&G theory to explore further some of the rudimentary grounds for the actions of the Malaysian audiences. Even though scholars have justified the idea that U\&G is a home-grown persuasion communication theory through which society understands and explores the motivation for media usage from an intrinsic socialpsychological context, in new media, especially OTT media, the implementation of this theory is still not widespread. This paper presents the intrinsic motivation through the use of the U\&G theory. The intrinsic reasons relate to the four principal characteristics:

\section{a. Information Seeking}

Knowledge seeking online is an up-to-date circumstance in the digital generation. For instance, in Indonesia, nearly every Internet user utilises YouTube to look for knowledge (Faroqi \& Suryanto, 2017). This implies that YouTube awards distinct experiences on how to obtain information in the digital epoch. It also signifies that the Internet TV has replaced linear TV (Ruggiero, 2000). This is likely since viewers choose the online content to gain new concepts and integrate with universal netizens, secure the information, exchange views, yield concepts, and further reinforce the cross-culture knowledge. Additionally, the notion of connected devices or things has promoted a new upsurge in the Internet, in which anything and anywhere can get linked with the Internet, which portrays the digital living way of life. Smart devices connect to the Internet and interact with each other, and then distribute the information, which can then be further treated to perform certain choices. Therefore, this article suggests that this presents a clear indication that the evolution of active audiences in the present-day lifestyle is hugely dependent on Internet access. Online content is a costeffective, dynamic, and straightforward means to gather information and updates, such as news and sports broadcasts through OTT media. Many OTT media providers were initially broadcasters that obtained a high demand from viewers for information seeking. These corporations are Sky News from international agencies, Fox News Channel, Al-Jazeera, ABC, CBC, and CNN, whereas popular news references for Malaysians are Astro Awani 501, Bernama TV, 1MalaysiaTV, myKlik (RTM), and KiniTV.

\section{b. Entertainment}

Liberalisation and democracy in the telecommunications area have provided numerous transformations in online applications, such as streaming video and online games. Entertainment is perhaps the characteristic that receives the most special consideration by researchers of OTT media viewers. It is crucial to recognise that media usage is inspired by a set of self-aware requests that encourage the audience to ardently look for online 
entertainment content for the satisfaction of those distinct needs via OTT media. Moreover, most of the OTT media players' marketing prototypes provide content that largely concentrates on entertainment (Tang \& Lee, 2016). Indeed, entertainment alternatives, such as serial dramas and films, are an essential part among the viewers for the OTT media medium. This article also recognises that global corporations, such as Show Now, Hulu Plus, Amazon Video, and Netflix, and national businesses such as Dimsum, HyppTV Everywhere, iFlix and Astro on-the-Go, offer entertainment content to viewers. Further, this article also recognises that Malaysian local horror films, especially 'Deadly: Azalea's Wrath', were broadcast on Netflix in August 2019, thereby suggesting that local content has hit the international business.

\section{c. Social}

In the evaluation of Rubin, he illustrated different approaches concerning how people get fun from television and recognised human needs in terms of gratification, such as closeness and emotional freedom. Finally, the results of his study demonstrate that television viewers value closeness compared to other components (Rubin, 1983). The study of Rubin described the behaviour of the audience as compared to the traditional media. Nonetheless, fresh analysis of new media has discovered that OTT media allows viewers to virtually interact with each other. Wagner (Wagner, 2016) declared that by binge-watching OTT media segments, viewers could interpret and communicate about current affairs that involve characters, themes, and plots with the people surrounding them. Besides, communicating in cyberspace could enhance the human experience among the viewers. Streaming programmes are flexible, which contrasts with linear TV programmes. Audiences can watch the preferred content whenever they want. Ultimately, meeting activity regularity with family members declines due to audience practice (Wagner, 2016) as binge-watching OTT media content results in limited time spent with friends and family. Ergo, this paper aims to investigate whether comparable circumstances are also relevant in the Malaysian setting.

\section{d. Escapism}

Additionally, the article also supports Herzog's (1944) previous research on radio listeners among homemakers in the United States, which proposed that they listen to it for various reasons, such as to overcome emotional stress, pass the time, or serve as a method of escapism to discover pleasure. Currently, media is recreated in the digital age, with new media studies like online games (Dux \& Kim, 2018) and YouTube (Faroqi \& Suryanto, 2017) continuing to follow the concept offered by Herzog and OTT media (Dias, 2016; Tang \& Lee, 2016). This indicates that viewers employing OTT media as a medium for getting what they need is not new. It was mentioned earlier that some people use media in their spare time or as part of their lifestyle, therefore, OTT media is used as a mechanism to overcome obstacles, such as loneliness, difficult times, anxiety, and social withdrawal. Hence, this article suggests that even though U\&G 2.0 was designed to discuss matters and interests linked to the new media, the original U\&G is still relevant in this study setting. The motive being is that some kinds of audience will utilise the media as a medium to eliminate problems, which usually serves as a short-term resolution. This is aligned with the idea presented beforehand (Katz \& Foulkes, 1962) that proposed that OTT media could lessen the weight of the predicament, but that it is not a long-term solution. Therefore, this study examines the employment of OTT media as an escapism action among Malaysian viewers and its association with pleasure. 


\section{Extrinsic Motives:}

Prior research indicated that, aside from the intrinsic factors, the viewer maintains bingewatching because it is dominated by external drives (Oliver, 2015) such as feedback, ratings, ads on various media mechanisms. We adopt ECT theory as its help to explain post-purchase or post-adoption satisfaction as a function of expectations, perceived performance, and disconfirmation of beliefs. Fudurić et al. (2018) proposed that convergence boosts convenience factors across different platforms and attractive pricing packages. This article explains that extrinsic motives relate to the four quintessential features below:

\section{a. Convenience}

The audiences of streaming facilities, especially on SVOD platforms, such as Amazon Prime Video, Hulu, and Netflix, are attuned to a distinctive way of enjoying online content in contrast to the linear TV. This is because OTT media offers a favourable experience to them. As Greer and Ferguson (Greer \& Ferguson, 2015) suggested in their study, the smartphone, tablet, personal computer, and iPad offer their users an alternative to conventional and large size TVs. They are handy to carry everywhere, and the user can watch OTT media in their place of choice. Additionally, TV networks rarely broadcast marathons of programmes. Consequently, the audience must wait and depend on fixed listed programmes (Schweidel \& Moe, 2016). This option liberates viewers and enables them to watch their desired content in their free time. Besides that, viewers often decide on a particular TV show based on recommendations and discussions online. For example, engaging captions, such as "Binge All Episodes Anytime" (Astro-on-the-Go), "See what is next" (Netflix), "Watch Anytime" (iFlix), and "Watch Everywhere. Watch Anything" (UniFi TV) tempt viewers to pick a distinct TV show for bingewatching. In addition to the above, previous studies show that the OTT media offers a 'web friendly TV' that improved viewers experience the best of TV and the best of the web in one seamless experience.

\section{b. Steer Clear of Advertisements}

Based on the audience experience of traditional TV programs, throughout this viewing session, users are exposed to ads. Viewers' exposures to advertisements vary based on the content they consume, as longer programs include more advertising than shorter programs (Schweidel \& Moe, 2016). However, more advanced scholars recommended that one of the external constituents that inspire audiences to subscribe to OTT media is that it empowers the audience to avoid commercial advertisements (Matrix, 2014). The advertisement business tends to profit by recognising the audiences as purchasers. Earlier, it was agreed that commercial broadcasting made the viewers a commodity locus in helping the industry to market its products and services. Indeed, various established media maintain their administration costs and produce revenue through advertising income. One of the impressive aspects of OTT media is that the viewers are allowed to skip the commercials. Therefore, engaged viewers have the option to stop watching linear broadcast channels and select the online video to obtain more empowerment over their media usage. Undeniably, the appearance of advertisements throughout the watching time is irritating (Schweidel \& Moe, 2016). With OTT media, viewers can experience and pick the variety of content as it enables the audience to binge-watch their requested content without commercial ads. This technological shift also spurs growing viewer's preference for over-the-top (OTT) streaming 
services is having a disruptive effect on traditional television not limited to scheduling, ratings, and advertising.

\section{c. Availability of Trial Period}

Client's expectations on the service furnished and practical experience will create a gap in service execution. As proposed in the ECT theory, if the anticipation can be completed positively, the customer will be happy. Nevertheless, if the service rendered does not satisfy the customer's expectations, a conflicting event will occur (Oliver, 2015). In the setting of modern marketing, the majority of business bodies, including OTT media players, instantly present trial sessions so that clients can enjoy it before deciding to subscribe to the facility. Nonetheless, from the communication and media aspects, the trial phase further strengthens the purchaser capacity with some expectations relating to the transforming feature of the content industries and media (Smits \& Nikdel, 2019). OTT media also presents a trial period so that the audience can see the programmes for free throughout the trial stage. It also affords some regulations and sufficient knowledge that permits users to undertake a free trial and commit to the right options, particularly for chargeable SVOD content. The trial period influences the opinions of viewers to subscribe to OTT media for a set term as it leads to a tangible sense for them. The trial period granted by OTT players in Malaysia can be summarised in Table 2.

Table 2: Free trial period offered by OTT Media players

\begin{tabular}{|c|c|c|c|c|}
\hline OTT Media & Tagline & $\begin{array}{l}\text { Free Trial } \\
\text { Period }\end{array}$ & Source & $\begin{array}{l}\text { Date of } \\
\text { Access }\end{array}$ \\
\hline Netflix & See what's next & 30 days & https://www.netflix.com/my/ & $\begin{array}{l}16 \text { Aug } \\
2020\end{array}$ \\
\hline Hulu Plus & $\begin{array}{l}\text { More Than Just } \\
\text { Live TV }\end{array}$ & 30 days & https://www.hulu.com/start/echoliveoffer & $\begin{array}{l}6 \text { Aug } \\
2020\end{array}$ \\
\hline $\begin{array}{l}\text { Amazon } \\
\text { Prime }\end{array}$ & Prime Video & 30 days & https://www.primevideo.com/ & $\begin{array}{l}6 \text { Aug } \\
2020\end{array}$ \\
\hline Iflix & $\begin{array}{l}\text { Why Steal When } \\
\text { You Can Get It } \\
\text { For Free? }\end{array}$ & 30 days & https://www.iflix.com/frequentlyasked.html\# & $\begin{array}{l}6 \text { Aug } \\
2020\end{array}$ \\
\hline $\begin{array}{l}\text { Astro on } \\
\text { the Go }\end{array}$ & $\begin{array}{l}\text { Binge All } \\
\text { Episodes } \\
\text { Anytime }\end{array}$ & $\begin{array}{l}\text { Limited } \\
\text { Promotion }\end{array}$ & https://astrogo.astro.com.my/ & $\begin{array}{l}6 \text { Aug } \\
2020\end{array}$ \\
\hline Dimsum & $\begin{array}{l}\text { Watch unlimited } \\
\text { Asian dramas \& } \\
\text { shows }\end{array}$ & 90 days & https://www.dimsum.my/welcome & $\begin{array}{l}6 \text { Aug } \\
2020\end{array}$ \\
\hline UniFi TV & $\begin{array}{l}\text { Watch } \\
\text { Everywhere. } \\
\text { Watch Anything. } \\
\text { Watch Anytime }\end{array}$ & 30 days & $\begin{array}{l}\text { https://unifi.com.my/tv/packages/unifi- } \\
\text { playtv.html }\end{array}$ & $\begin{array}{l}6 \text { Aug } \\
2020\end{array}$ \\
\hline
\end{tabular}

\section{d. Price}

Unlike free-to-air TV, pay-TV and OTT media providers impose a subscription fee on the subscribers. The costs could be based on a pay per view or monthly basis. Predominantly, most powerful content providers charge more expensive rates to content sellers that might upset the client. Brynjolfsson and his team (Brynjolfsson, Smith, \& Hu, 2003) provided empirical evidence that suggested that customers appear attracted to buy something that they have an influence on that determines their value and fondness. Merikivi et al. (2016) also 
suggested that OTT media players that offer streaming services prefer the binge-watching type that exhibits an obvious competitive over free-to-air TV and pay-TV providers. This effect causes rising tension among their rivals. Due to the latent fight in the video streaming business, the majority of OTT media players present aggressive prices to monopolise the market. When there is adequate competition, users own more suitable alternatives to determine the subscription to the OTT media providers. This article aims to relate consumer behaviour that involves extrinsic elements, such as inexpensive rates, which might encourage users to subscribe to OTT media. Hence, this paper further examines the subscription fee and the willingness to pay as these are the essential extrinsic motivations for users in determining whether to subscribe to OTT media.

\section{e. Censorship}

Malaysia is a nation governed by laws, not by individuals neither industry. Since the earliest days of the founding of the Malaysia, there are several pieces of legislation which confer of public interest. Two important facts in justifying polices and rules are pre-emptive and penitentiary with aimed to ensure long term benefits of the end users. Prior to market liberalization, telecommunication and broadcasting industry were separate markets. However, in 2002, the government strip away the sectoral Acts and replaced with the Communications and Multimedia Act 1998 (CMA 1998), to facilitate convergence in ICT related activities. Thus, the CMA 1998 has been designed and formulated to support both technology and service neutral (Safinaz, 2005).

On the other hand, Malaysian Communications and Multimedia Commission (MCMC) is of the view that OTT services should be classified as different markets due to different playing fields as compared to the traditional broadcasters (MCMC, 2015). Thus, no regulation imposed by the Commission at this juncture as most of OTT communication such as WhatsApp and Telegram offers "freemium" costs to the consumers (Baldry, Steingröver, \& Hessler, 2014). However, some countries have taken different approaches. In China, Greece and other conservatives societies, censorship was considered a one of the instrument for regulating the moral and political life of the population (Newth, 2010). In Singapore, the government imposed media regulation whether the media advocates sexual violence and promotes homosexuality (Wu \& Koo, 2001). The Chinese government has also held close control over the media as a means of promoting moral and social values (Brown et al., 2013). Malaysia, has yet to inaugurate a regulatory framework for content that can be accessible via OTT platform. OTTs have an opportunity for growth due to increased streaming volume, but in order to protect the general public, the government should also consider censorship content to curb sex scenes and LGBT representation on OTT media's films and TV shows. Thus, this study adopt public interest theory developed by Arthur Cecil Pigou (1960s) to explain regulation seeks the protection and benefit of the general public in particular in Malaysia.

In order to fill up the gap, this article builds an integrated conceptual framework to take the motives as a whole process for audiences watching OTT media to attain gratification. This article combines Uses and Gratification Theory (U\&G) and Expected Confirmation Theory (ECT) as the foundation for intrinsic and extrinsic motives and content regulation as the basis for 'public interest' factor to reflect the nature of benefits and evaluation, and to explain users' rational behaviour during the whole process of audience's decision to watch OTT media. This study examines the effects of motives on satisfaction. We adopt satisfaction because it has been demonstrated that it is key to retaining a loyal viewer base. Basically, 
satisfaction is a summary outcome demonstrating a level of approval that viewer's motives to their experience. Consider OTT media players among others are Netflix, iflix, Viu and TonTon that currently available in Malaysia have large program catalogue, supply of diverse original content, flexible availability, affordable price, and lack of ad reliance allow the audiences to obtain the information, entertainment, socializing and escape from the pandemic moment.

Based on the discussion above, the principle of attribute for the conceptual framework of this paper can be summarised as below (Figure 3 ).

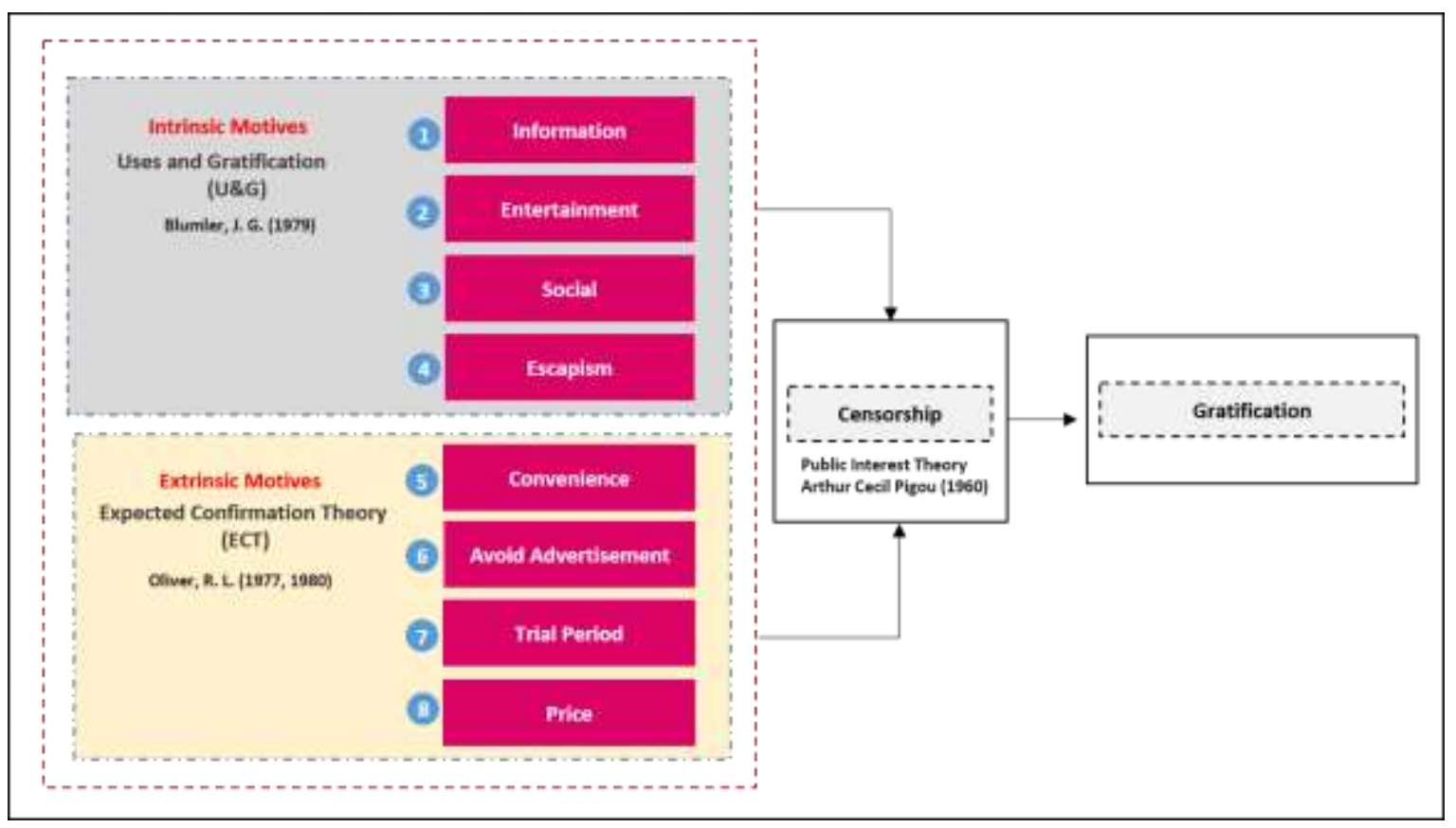

Figure 3: Theoretical Framework

We strongly believe that this study should be able to extends the media and communication research in three important ways:

a. Strengthen and enrich the media and communication research to address the intrinsic and extrinsic motives as need satisfaction in the OTT media content;

b. Extends the scope of media and communication research by testing whether the proposed framework essential role of the satisfaction of intrinsic and extrinsic motives

c. contribution to knowledge by combining three theories namely UGT, ECT and public interest theory to explain and predict the behaviour and perception the audiences in Malaysia

\section{CONCLUSION}

Hence, this notion describes the intrinsic and extrinsic motives that drive the audience in Malaysia to shift to Web TV to achieve pleasure. Most importantly, this article recognises and confers the possible motivations of media consumption from the integration of U\&G and ECT theories to explain audience intrinsic and extrinsic motives. Ultimately, it presents an exhaustive perception of the dynamics around users' intrinsic motives, which include information seeking, entertainment, social, and escapism. As for the extrinsic motives, it was the convenience, avoiding the advertisements, trial period, and price that determine their purchase decision to subscribe to OTT media. The suggested conceptual framework could be 
implemented to conduct a hybrid variety of media programming based on actual audience behaviour. Nonetheless, this paper must establish the conceptual framework competency. Ergo, this paper continues to examine further to administer and review the suggested framework.

\section{BIODATA}

Asma Md Isa is a PhD candidate at the Centre for Research in Media \& Communication (MENTION), Faculty of Social Sciences \& Humanities (FSSK), The National University of Malaysia.Email: asmaisa@tm.com.my

Wan Amizah Wan Mahmud is an Associate Professor at the Centre for Research in Media \& Communication (MENTION), Faculty of Social Sciences \& Humanities (FSSK), The National University of Malaysia. Email: wan_amizah@ukm.edu.my

Wan Idros Wan Sulaiman is a Senior Lecturer at the Centre for Research in Media \& Communication (MENTION), Faculty of Social Sciences \& Humanities (FSSK), The National University of Malaysia. Email: wiws@ukm.edu.my 


\section{REFERENCES}

Asma Md. Isa, Wan Amizah Wan Mahmud, Wan Idros Wan Sulaiman, \& Muhammad Adnan Pitchan. (2019). Netflix and dilemma of content regulation in Malaysia. International Journal of Advanced Science and Technology, 28(16), 460-468. Retrieved from http://sersc.org/journals/index.php/IJAST/article/view/1782

Baldry, S., Steingröver, M., \& Hessler, M. A. (2014). The rise of OTT players - What is the appropriate regulatory response?. International Telecommunications Society Regional Conference (pp. 22-25). Brussels.

Becot, S., Bertin, E., Crom, J.-M., Frey, V., \& Tuffin, S. (2015). Communication services in the web era: How can telco join the OTT hangout?. 18th International Conference on Intelligence in Next Generation Networks. France, Paris: Institute of Electrical and Electronics Engineers (IEEE). https://doi.org/10.1109/ICIN.2015.7073833

Brown, J. D., Zhao, X., Wang, M. N., Liu, Q., Lu, A. S., Li, L. J., ... Zhang, G. (2013). Love is all you need: A content analysis of romantic scenes in Chinese entertainment television. Asian Journal of Communication, 23(3), 229-247. https://doi.org/10.1080/01292986.2012.729148

Brynjolfsson, E., Smith, M. D., \& Hu, Y. (Jeffery). (2003). Consumer surplus in the digital economy: Estimating the value of increased product variety at online booksellers. Massachusetts, USA.

Dias, P. (2016). Motivations for multi-screening: An exploratory study on motivations and gratifications. European Journal of Communication, 31(6), 678-693. https://doi.org/10.1177/0267323116674111

Digital TV Research. (2016). Asia pacific SVOD forecasts table of contents. Middlesex, UK: Author.

Dux, J., \& Kim, J. (2018). Social live-streaming: Twitch.TV and uses and gratification theory social network analysis. Computer Science \& Information Technology, 47.

Faroqi, A., \& Suryanto, T. L. M. (2017). Why Indonesian users visiting YouTube an exploration of uses and gratification theory. 3rd International Joint Conference On Science And Technology at: Bali Nusa Dua Convention Center, Indonesia. Bali, Indonesia. https://doi.org/10.13140/RG.2.2.32630.70726

Fudurić, M., Malthouse, E. C., \& Viswanathan, V. (2018). Keep it, shave it, cut it: A closer look into consumers' video viewing behavior. Business Horizons, 61(1), 85-93. https://doi.org/10.1016/j.bushor.2017.09.008

Ganuza, J. J., \& Viecens, M. F. (2014). Over-the-top (OTT) content: implications and best response strategies of traditional telecom operators. Evidence from Latin America. Info, 16(5), 59-69. https://doi.org/10.1108/info-05-2014-0022

Greer, C. F., \& Ferguson, D. A. (2015). Tablet computers and traditional television (TV) viewing: Is the iPad replacing TV? Convergence, 21(2), 244-256. https://doi.org/10.1177/1354856514541928

Hegedus, K. (2016). Global audience demand for digital original series. Cannes, France: MIPTV. Ida Lim. (2020). MCO: Malaysians stuck at home give Netflix, Tonton biggest traffic growth rates against competitors. Retrieved on September 5, 2020, from https://www.malaymail.com/news/malaysia/2020/04/01/mco-malaysians-stuck-athome-give-netflix-tonton-biggest-traffic-growth-rat/1852432

Katz, E., \& Foulkes, D. (1962). On the use of the mass media as "escape": Clarification of a concept. Public Opinion Quarterly, 26(3), 377-388. https://doi.org/10.1086/267111 
Latiff, D. I. A., Ridzuan, A. R., Mohideen, R. S., Anuar, N. K. K., \& Shukri, N. A. M. (2016). A study of usage patterns and tv shows analysis on internet TV. Journal of Education and Social Sciences, 3(2012: Feb.), 111-117.

Lavanya, R., \& Ramanchandran, V. (2011). Cloud based video on demand model with performance enhancement. Malaysian Journal of Computer Science, 24(2), 73-83.

Manovich, L. (2001). The language of new media. Screen (Vol. 27). Massachusetts, USA: MIT Press. https://doi.org/10.1386/nl.5.1.25/1

Matrix, S. (2014). The Netflix effect: Teens, binge watching, and on-demand digital media trends. Jeunesse: Young People, Texts, Cultures, 6(1), 119-138. https://doi.org/10.1353/jeu.2014.0002

MCMC. (2015). MCMC., myConvergence, Issue 13. Retrieved on May 22, 2020, from https://www.mcmc.gov.my/skmmgovmy/files/d5/d5f6528a-8468-45df-a212b21ce44f0b18/files/assets/basic-html/page-56.html

Merikivi, J., Mantymaki, M., Salovaara, A., \& Zhang, L. (2016). Binge watching television shows: Conceptualization and measurement. Twenty-Fourth European Conference on Information Systems (ECIS). Istanbul, Turkey: AIS Electronic Library (AISeL).

Mulder, A. (2006). Media. Theory, Culture \& Society, 23(2-3), 289-296. https://doi.org/10.1177/0263276406062683

Newth, M. (2010). The long history of censorship. Retrieved on September 1, 2020, from http://www.beaconforfreedom.org/liste.html?tid=415\&art_id=475

Oliver, R. L. (1980). A cognitive model of antecedents and consequences of satisfaction decisions. Journal of Marketing Research, 17(4), 460-469. https://doi.org/10.2307/3150499

Oliver, R. L. (2015). Satisfaction: A behavioral perspective on the consumer ( $2 \mathrm{nd}$ ed.). New York: Taylor \& Francis Group.

Parliament of Malaysia. (2019). Hansard house of representative: Second term. 14th Parliamentary Session, 2(11). Kuala Lumpur: Author.

Rubin, A. M. (1983). Television uses and gratifications: The interactions of viewing patterns and motivations. Journal of Broadcasting, 27(1), 37-51. https://doi.org/10.1080/08838158309386471

Ruggiero, T. E. (2000). Uses and gratifications theory in the 21st century. Mass Communication and Society, 3(1), 3-37. https://doi.org/10.1207/S15327825MCS0301_02

Safinaz Mohd Hussein. (2005). Service provider licensing system in the Malaysian communications and multimedia industry. 18th BILETA Conference: Controlling Information in the Online Environment (pp. 1-6). London, United Kingdom: The British and Irish Law Education Technology Association (BILETA).

Schweidel, D. A., \& Moe, W. W. (2016). Binge wathcing and advertising. Journal of Marketing, 80(5), 1-9. https://doi.org/10.1360/zd-2013-43-6-1064

Smits, R., \& Nikdel, E. W. (2019). Beyond Netflix and Amazon: MUBI and the curation of ondemand film. Studies in European Cinema, 16(1), 22-37. https://doi.org/10.1080/17411548.2018.1554775

Sterling, C. H., \& Kittross, J. M. (2002). Stay tuned: A history of American broadcasting (Vol. 53). New Jersey: Lawrence Erlbaum Associates, Publishers. https://doi.org/10.1017/CBO9781107415324.004 
Tang, H. N., \& Lee, Y. C. (2016). Over-the-top (OTT) instant messaging (IM) service loyalty from the perspective of vietnamese user. Indian Journal of Science and Technology, 9(46). https://doi.org/10.17485/ijst/2016/v9i46/107863

Wagner, C. N. (2016). Glued to the sofa: Exploring guilt and television binge-watching behaviors. San Antonio, Texas: Trinity University.

Wu, W., \& Koo, S. H. (2001). Perceived effects of sexually explicit internet content: The thirdperson effect in Singapore. Journalism and Mass Communication Quarterly, 78(2), 260-274. https://doi.org/10.1177/107769900107800204 